\title{
An experimental model of the Ross operation: Development of resorbable reinforcements for pulmonary autografts
}

\author{
Francesco Nappi, MD, ${ }^{\mathrm{a}}$ Cristiano Spadaccio, $\mathrm{MD}, \mathrm{PhD},{ }^{\mathrm{b}}$ Pierre Fouret, $\mathrm{MD}, \mathrm{PhD},{ }^{\mathrm{c}}$ \\ Nadjib Hammoudi, MD, ${ }^{\mathrm{d}}$ Juan Carlos Chachques, MD, PhD, ${ }^{\mathrm{e}}$ Massimo Chello, $\mathrm{MD},{ }^{\mathrm{f}}$ and \\ Christophe Acar, $\mathrm{MD}, \mathrm{PhD}^{\mathrm{g}}$
}

\begin{abstract}
Objectives: To circumvent the issue of pulmonary autograft (PA) dilation after the Ross procedure, surgical reinforcement strategies have been suggested in clinical or anecdotal series. However, no preclinical large-animal model of the Ross procedure is available, which is needed to enable full comprehension of the pathologic mechanisms and the effectiveness of reinforcement techniques during growth. Our aim was to develop a large-animal model of the Ross operation, to reproduce the clinical scenario in which this procedure might be applied, and allow for development and testing of various devices and techniques to improve PA performance. In addition, we aimed to test the effectiveness of a bioresorbable mesh for PA reinforcement.
\end{abstract}

\begin{abstract}
Methods: An experimental model of transposition of the pulmonary trunk as an autograft in the aortic position has been developed and performed under cardiopulmonary bypass in 20 growing lambs, aged 3 months. The experimental design included: a control group that underwent PA transposition; a group in which the PA was reinforced with an external, synthetic, nonresorbable, polypropylene grid; and a group that received various combinations of resorbable meshes. Animals were followed up during growth for 6 months by angiography and echocardiography and eventually killed for pathologic analysis.
\end{abstract}

Results: All animals survived the procedure with no complications. The model was easy and reproducible. Resorbable meshes prevented PA dilation and preserved its progressive growth process, aiding histologic remodelling.

Conclusions: We developed an easy and reproducible model of the Ross procedure, allowing for a reliable simulation of the clinical scenario. Resorbable PA reinforcement may represent an interesting option in this context. (J Thorac Cardiovasc Surg 2015;149:1134-42)

See related commentary on pages $1142-3$.

The Ross procedure is currently at the center of a lively scientific debate and is gaining favor among many groups that consider the pulmonary valve autograft to be an ideal replacement for the aortic valve, ${ }^{1-4}$ especially in neonates

From the Cardiac Surgery Centre Cardiologique du Nord de Saint-Denis, ${ }^{a}$ Paris, France; Department of Cardiothoracic Surgery, ${ }^{b}$ Golden Jubilee National Hospital, Clydebank, Glasgow, United Kingdom; Departments of Pathology ${ }^{\mathrm{c}}$ and

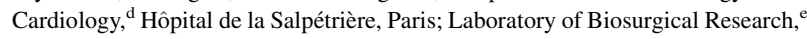
Carpentier Foundation, Pompidou Hospital, University Paris Descartes, Paris, France; Department of Cardiovascular Surgery, ${ }^{\mathrm{f}}$ University Campus Bio-Medico of Rome, Rome, Italy; and Department of Cardiovascular Surgery, ${ }^{\mathrm{g}}$ Hôpital de la Salpétrière, Paris, France.

This work was partially supported by the Girolomo Orlando Foundation (Pescopagano, Italy) during experimental activities. Experimental activities were performed at Laboratory of Biosurgical Research, Carpentier Foundation, Pompidou Hospital, University Paris Descartes, Paris, France.

Disclosures: Authors have nothing to disclose with regard to commercial support.

Received for publication Oct 12, 2014; revisions received Dec 6, 2014; accepted for publication Dec 28, 2014; available ahead of print Feb 4, 2015.

Address for reprints: Francesco Nappi, MD, Cardiac Surgery Centre Cardiologique du Nord de Saint-Denis, 36 Rue des Moulins Gémeaux, 93200 Saint-Denis, France (E-mail: francesconappi2@gmail.com).

$0022-5223 / \$ 36.00$

Copyright (C) 2015 by The American Association for Thoracic Surgery

http://dx.doi.org/10.1016/j.jtcvs.2014.12.056 and children, ${ }^{5-9}$ given its potential to grow over time. Although this idea remains appealing, the potential for pulmonary autograft (PA) dilation and failure in growing children has led to reconsideration of the importance of this operation and reappraisal of other approaches.

From a technical point of view, the transposition of the pulmonary root, consisting of both the pulmonary trunk and pulmonary valve (freestanding root replacement), with reimplantation of the coronary ostia, has progressively overthrown the originally described subcoronary implantation technique. ${ }^{10-13}$ However, cases of aneurysmal formation ${ }^{14,15}$ have been described, as well as aortic valve insufficiency caused by overstretching on the commissural areas with cusp restriction and a central lack of coaptation. ${ }^{16,17}$ Acknowledgement of this limitation led some authors to reevaluate the subcoronary freehand technique. ${ }^{18,19}$ However, owing to the risk of autograft valve distortion resulting in residual regurgitation, full root replacement has remained the only reliable method to apply the Ross procedure in patients who are still growing. Nevertheless, the non-negligible risk of reoperation associated with the Ross procedure root replacement in the pediatric age group has prompted caution statements from several groups regarding the potential of the procedure, ${ }^{20-22}$ and triggered novel efforts to circumvent this issue. 


\section{Abbreviations and Acronyms \\ $\mathrm{PA}=$ pulmonary autograft \\ $\mathrm{PDS}=$ polydioxanone \\ $\mathrm{PG}=$ polyglactin}

Designed to address the problem of autograft root dilatation, various methods of pulmonary artery trunk reinforcement with a prosthesis have produced encouraging results. ${ }^{23-25}$ However, these data came from single centers or single-surgeon, individual experience. Complete sets of experimental activities are needed to help enable a full evaluation of the morphologic, pathologic, and hemodynamic aspects of the proposed reinforcement strategy, and more importantly, a progressive follow-up of the vascular changes during growth.

A preclinical, large-animal model of the Ross procedure has not been developed; such a model might allow for development and testing of various devices and techniques to improve PA performance. Porcine models are not amenable to long-term testing or analysis, as would be needed. The frequently used ovine models are not suitable for simulating an actual Ross procedure, because of anatomic constraints. Both the ascending aorta and pulmonary artery trunk are too short to be handled, and the coronary ostia are anatomically situated in an extremely low position, which makes their reimplantation on the PA difficult. In this context, we developed an experimental model of PA transposition in the growing lamb, which allows for an optimal reproduction of the clinical scenario in which the Ross procedure might be applied. Having established an adequate model, we also tested an experimental approach of in vivo PA reinforcement in the growing lamb.

\section{METHODS}

\section{Experimental Protocol}

With the aim of simulating the pediatric clinical situation, an experimental model of transposition of the pulmonary trunk as an autograft in the aortic position has been developed and performed using cardiopulmonary bypass in 20 growing lambs. Technical and anatomic issues necessitated reimplantation of the PA in the descending aorta, with the pulmonary trunk being replaced by a homograft from another lamb of the same age and weight (Figure 1). The age of the animals at the time of the implant was 3 months (11-12 weeks), and baseline mean weight was about $27 \pm 2 \mathrm{~kg}$, allowing observation of the progression of the autograft diameter during the period of fastest growth.

In addition to PA transposition (control group, $\mathrm{n}=4$ ), the experimental design included a group in which the PA was reinforced with an external, synthetic, nonresorbable grid polypropylene just before implantation (nonresorbable group, $\mathrm{n}=4$ ), and a third group that received a resorbable mesh as PA reinforcement (resorbable group, $\mathrm{n}=12$ ). The latter was divided into a subgroup that was reinforced with a commercially available 4-layer, knitted polydioxanone (PDS) mesh (Ethicon, Inc, Somerville, NJ) (subgroup PDS, $\mathrm{n}=4$ ), a subgroup receiving a 4-layered polyglactin $(\mathrm{PG})$ mesh (Ethicon) (subgroup PG, $\mathrm{n}=4$ ), and a group in which PA was reinforced with a crosslinked mesh made of a single PG layer strengthened by an interlaced PDS suture (subgroup PDS/PG, $\mathrm{n}=4$ ). All animal experiments were performed at Laboratory of Biosurgical Research, Carpentier Foundation, Pompidou Hospital, University Paris Descartes (France) according to guidelines for animal care and handling. The protocol was approved by the institutional animal care committee at Carpentier Foundation, Pompidou Hopital.

\section{Surgical Model}

Lambs were premedicated with ketamine ( $25 \mathrm{mg} / \mathrm{kg}$ intramuscularly), and anesthesia was guaranteed by injection of sodium thiopentothal $(6-8 \mathrm{mg} / \mathrm{kg})$ via the internal jugular. Animals received $100 \mathrm{mg}$ of lidocaine intravenously, as prophylaxis against rhythm disturbance. After endotracheal intubation, ventilation was provided until animal awakening, and anesthesia was maintained with inhalation isoflurane $(1 \%-2.5 \%)$. The electrocardiogram was monitored. The chest was prepared and shaved. The heart was approached via left thoracotomy.

After the pericardium was opened, the right atrium was exposed for cannulation, and the trunk of the pulmonary artery was dissected to free it, extending from its right ventricular point of origin up to its bifurcation in the pulmonary arteries. The same was done for the descending thoracic aorta, and a region distal to the portion of choice for the PA transposition was cannulated (Figure 1). Approximately $8 \mathrm{~cm}$ of the descending thoracic aorta was left for clamp positioning and to perform the anastomosis with the pulmonary artery trunk under optimal conditions. Three $\mathrm{mg} / \mathrm{kg}$ of heparin was given intravenously, and cardiopulmonary bypass was started between the right atrium and descending aorta. The cerebral circulation of the animal was guaranteed by a beating heart. Three $\mathrm{cm}$ of the pulmonary artery trunk was transposed into the descending aorta with an end-to-end anastomosis in 5-0 polypropylene (Prolene; Ethicon, Inc) (Figure 2). A fresh pulmonary artery homograft, explanted from animals killed on the same day for another experimental study, was inserted to reconstruct the right outflow tract, with a proximal and distal end-to-end anastomosis in 5-0 polypropylene (Prolene), as in the Ross operation. Left thoracotomy was closed and aspiration drainage was left in place.

Before implantation, the PA was reinforced with various meshes, according to study design (Figure 1). The resorbable mesh was prepared at the operative table (time: $10 \pm 2$ minutes) and was designed to minimize radial tension. The larger diameter openings of the resorbable meshes, and their arrangement, have been constructed to allow multidirectional PA growth. Meshes exhibit a progressively higher degree of density and thickness at the level of the Valsalva sinuses and the sinutubular junction, which suffer most from dilatative degeneration. Going from the annulus to the distal end (the level of the sinutubular junction), both density and undulation increase.

Meshes used in this study were cut into a rectangle $20 \mathrm{~mm}$ in height, to match the height of the autograft, and rolled out on a metallic candle and sutured to create a cylinder with an internal diameter of $10 \mathrm{~mm}(20 \mathrm{~mm}$ in height, with $10 \mathrm{~mm}$ diameter directly adhered to the PA) (Figure 2). After this step, the autograft was inserted into the fibrillar cylinder and anastomosed, with both its margins and those of the prosthetic structure sutured to the pulmonary autograft trunk. The mesh was oriented to allow maximal extensibility in the longitudinal direction (which allows growth in length) and minimal transverse extensibility (limiting enlargement of the diameter).

\section{Data Acquisition}

Animals underwent 2 sets of angiographic and echocardiographic measurements, at day 1, and 6 months postoperatively. Eventually, animals were humanely killed, and their tissues were harvested for histopathologic analysis. Measurements of the ascending aorta and descending aorta, proximally and distally to the autograft, were made to obtain a reference for comparison with the diameter of the PA. A weight curve for each animal was processed in parallel during the growth period. The diameter of the PA was determined by arteriography of the autograft in its systemic position using radiopaque markers to determine the diameter of its basal side, and its height. 


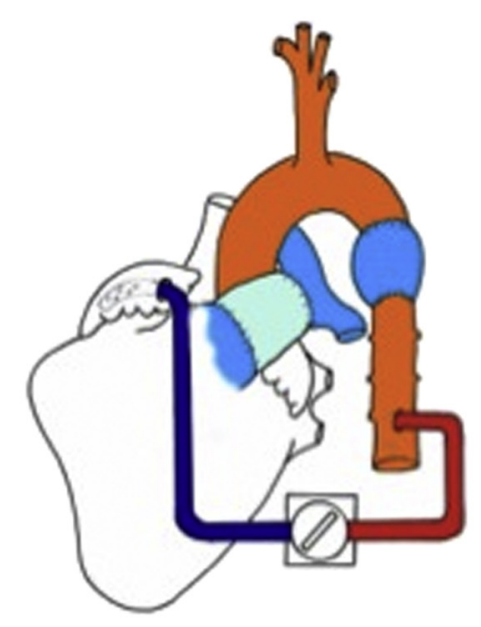

A
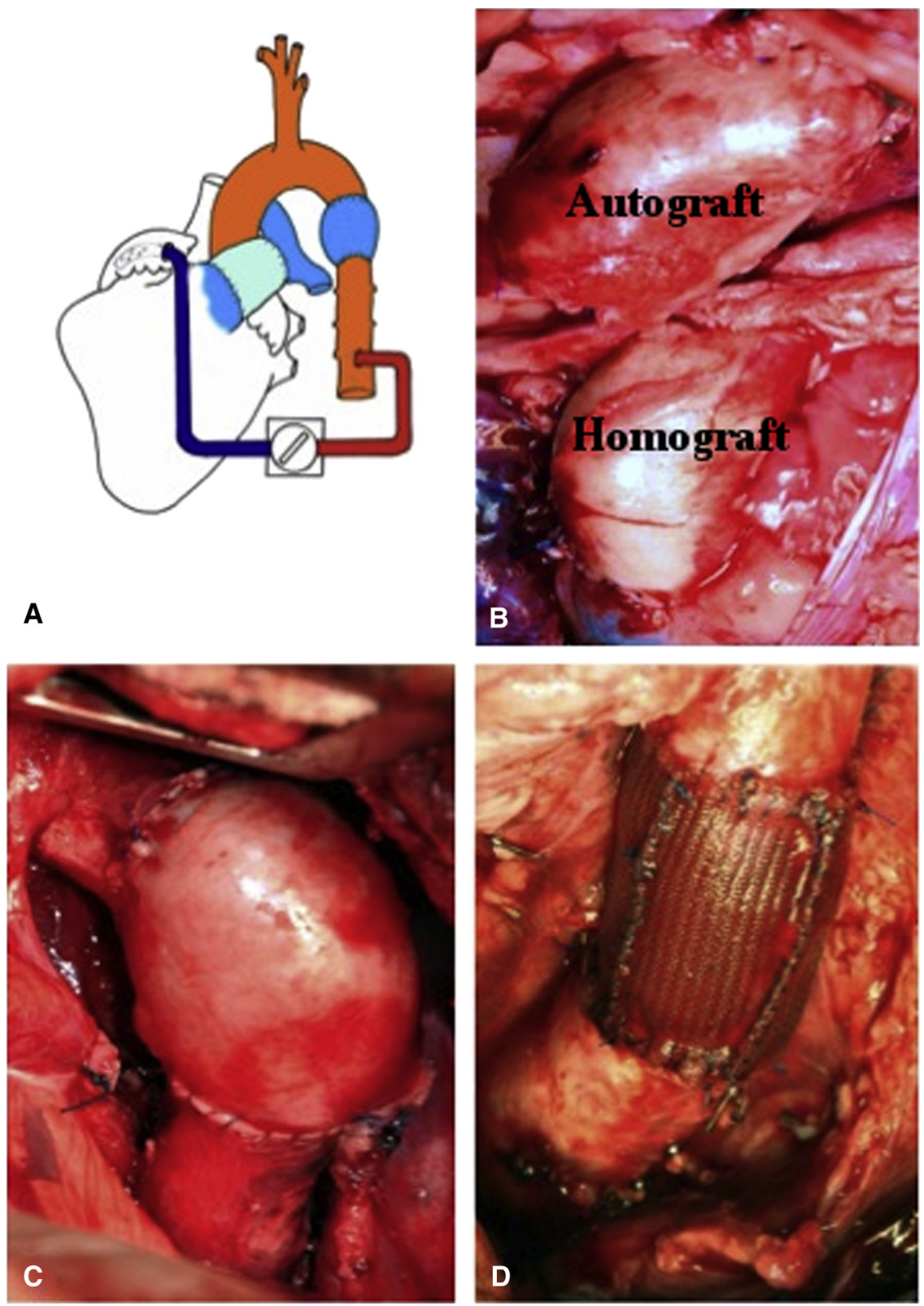

FIGURE 1. A, Schematic drawing of surgical setup for cardiopulmonary bypass. B, Surgical view of homograft and autograft transposition. C, Example of PA transposition, without reinforcement, after 6 months. D, Example of PA transposition, with reinforcement, after 6 months.

Given the close anatomic relationship of the descending aorta with the esophagus in the lamb, transesophageal echography was additionally used to assess the size of the autograft. ${ }^{26}$ This measurement was made at day 1 , using a short-axis view. The descending aorta immediately distal to the graft was used as a reference value. When the animals were killed, the PAs were examined, and the severity of adhesions with neighboring structures was evaluated with a graded scale based on anatomic parameters from 1 to 3 . The PAs were fixed and processed for hematoxylin and eosin, as well as Masson's trichrome, staining.

\section{Statistical Analysis}

Continuous data are presented as mean $\pm \mathrm{SD}$. Continuous variables were compared using the unpaired Student $t$ test, and 1-way ANOVA was performed to compare groups with different reinforcements, followed by a multiple pairwise comparison procedure. $P$ values of $<.05$ (2-tailed) were taken to indicate statistical significance. Analysis was performed with SPSS version 20.0 (SPSS, Inc, Chicago, Ill).

\section{RESULTS}

\section{Surgical Outcome}

All animals survived the procedure and did not experience surgical complications. A case of PA initial rupture and thrombosis occurred at 6 months during the followup, in the control group, without causing animal death. 

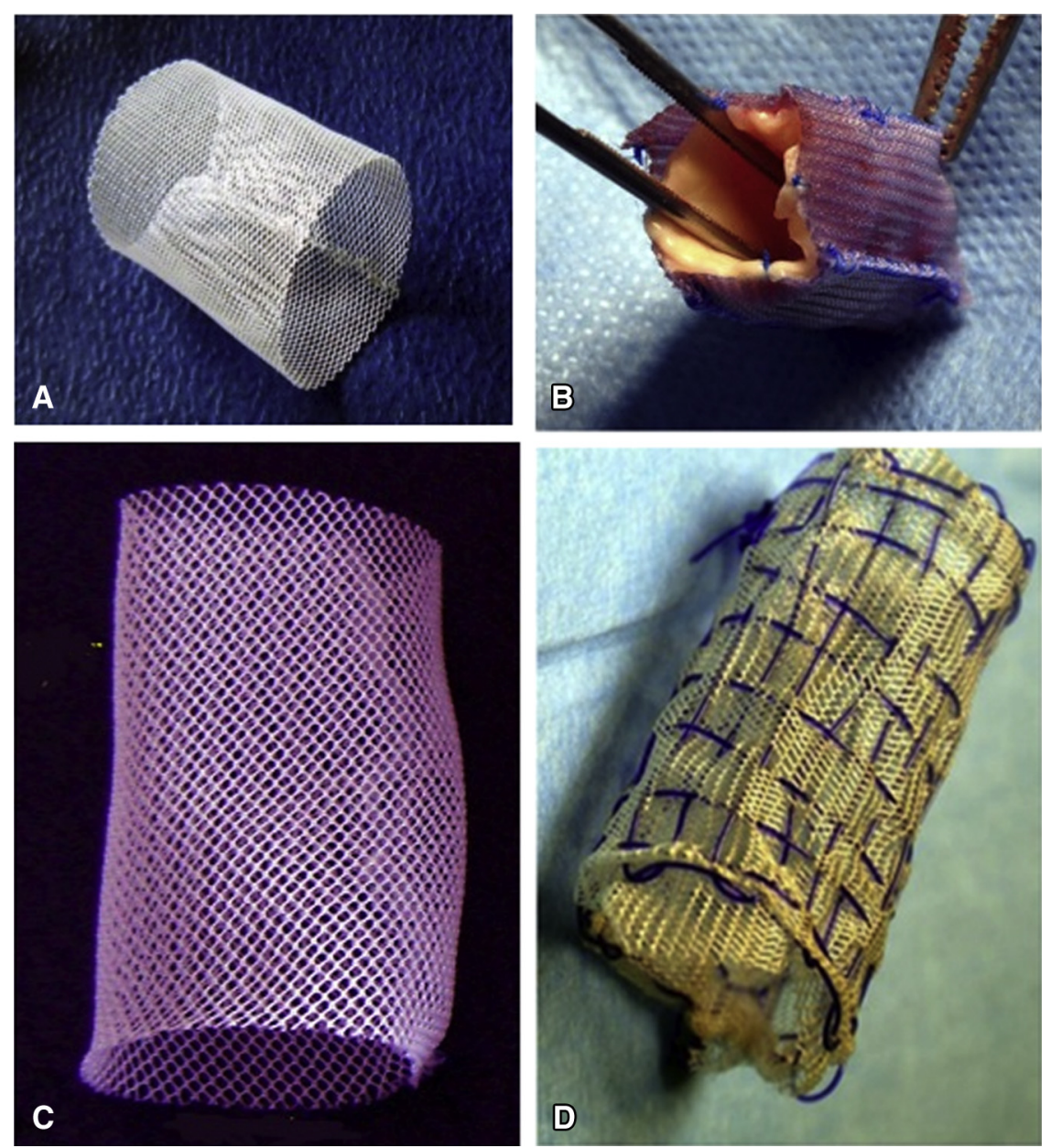

FIGURE 2. Various types of reinforcement mesh used in the study: (A) polypropylene; (B) polyglactin; and (C) polydioxanone. These materials are commercially available in the form of fibrillar meshes (Ethibond, Vicryl, and PDS, respectively; Ethicon, Inc, Somerville, NJ). D, Handmade crosslinked polyglactin/polydioxanone prosthesis.

The procedure did not pose particular technical challenges. At 6 months, animal weight was doubled $(27 \pm 5 \mathrm{~kg}$ at day 0 , and $55 \pm 10 \mathrm{~kg}$ at 6 months), suggesting a normal growth process.

\section{Angiographic Study}

The angiographic evaluation was performed with direct contrast-medium infusion into the aortic root (Figure 3, $A-C[D-F$ are discussed in the next section]). The reference aortic diameter increased from $14 \pm 1 \mathrm{~mm}$ to $19 \pm 2 \mathrm{~mm}$. In the control group, an instantaneous PA distension ( $26 \pm 2$ $\mathrm{mm})$ was noted, followed by aneurysm development at month 6 (39 $\pm 3 \mathrm{~mm}, P<.001$ vs reference), with a $56 \%$ diameter increase with respect to day 0 , and an indexed ratio of 2.05 with respect to the reference (Figure 4, A). We encountered 1 case of partial rupture and intraluminal thrombosis.

In the group with nonresorbable polypropylene, the graft diameter increased initially $(18 \pm 1 \mathrm{~mm})$, but remained stable at 6 months $(20 \pm 1 \mathrm{~mm}$; indexed ratio, 1.05 ; overall increase, $5 \% ; P=.4$ ), and the size match with the descending aorta was excellent (Figure 4, $B$ ). In the resorbable matrix groups, a minimal distension at day 1 , followed by a slight but significant increase in diameter over the course of 6 months, could be seen. The mean diameter was $28 \pm 2 \mathrm{~mm}$, and no statistically significant difference was found among the various resorbable materials (Figure 4, C). The PDS/PG subgroup showed an initial dilation $(18 \pm 1 \mathrm{~mm})$ and a slight increase in diameter at 6 months $(27 \pm 2 \mathrm{~mm})$, with an overall increase of $42 \%$ and an indexed ratio of 1.42. In addition, the reference aorta diameter increased by $34 \%$ and, based on curve slopes, only the PA with resorbable reinforcement material behaved similarly to the normal aorta in the growing lamb (slope $1.4 \%$ and $1 \%$, respectively) (Figure $4, D$ ).

\section{Transesophageal Echography}

The control group without reinforcement showed an instantaneous distension of up to $27.4 \pm 0.55 \mathrm{~mm}$, whereas the reference diameter was $16 \mathrm{~mm}$ (Figure 3,D-F). The 

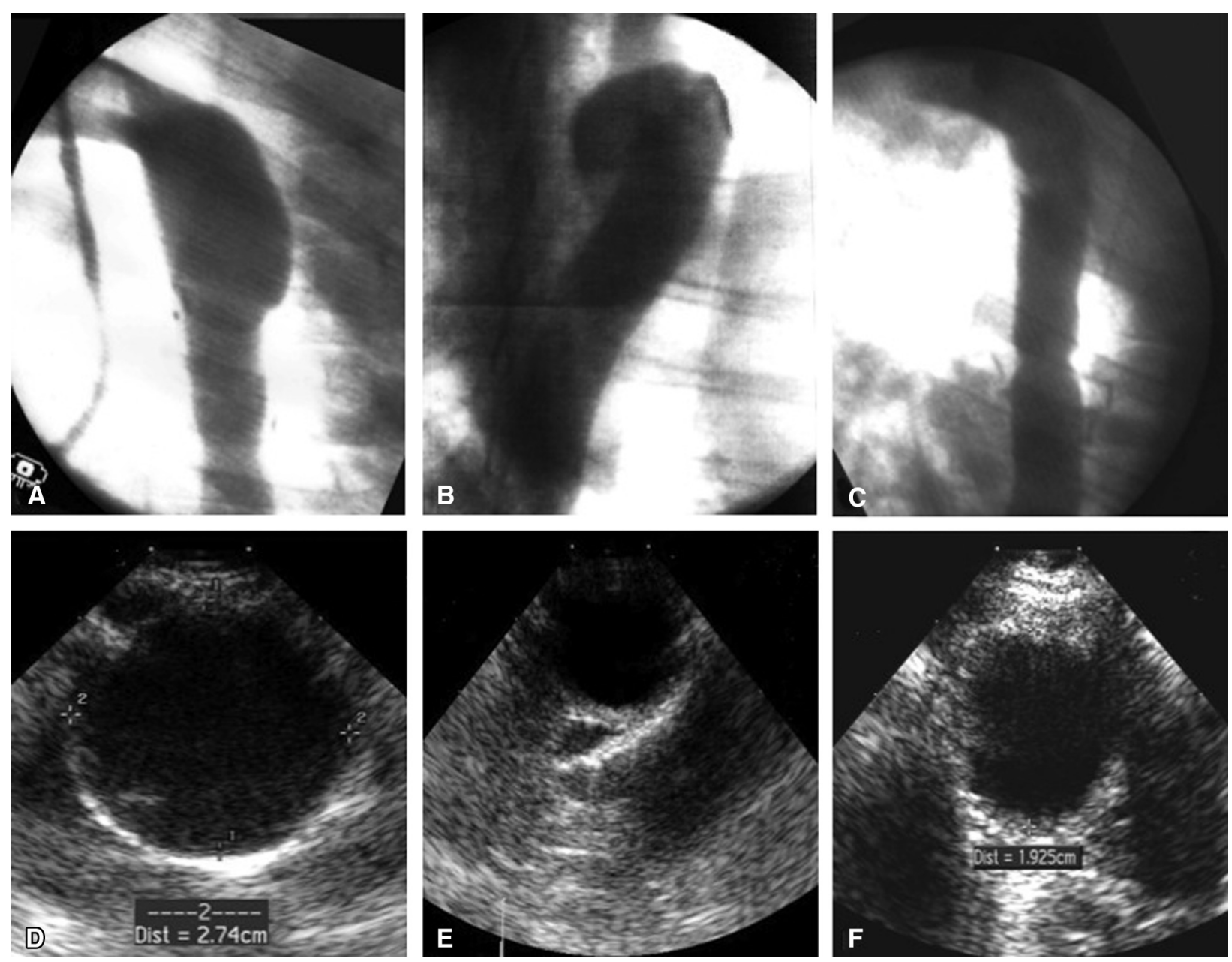

FIGURE 3. Representative angiography study for the following groups: (A) control; (B) nonresorbable; and (C) resorbable. Representative transesophageal images from the following groups: (D) control; (E) nonresorbable; and (F) resorbable. Dist, Distance.

autograft that was protected with polypropylene showed a very limited increase in diameter at day 1 , compared with the reference diameter (Figure 3). At 6 months, all measurements were repeated. In all unprotected PAs, a considerable increase in size was noted, with a true aneurismal formation $(36.3 \pm 1.7 \mathrm{~mm}$ vs $19 \pm 1.6 \mathrm{~mm})$ at the level of the descending aorta. Meanwhile, the reference diameter of the aorta increased from 14 to $19 \mathrm{~mm}$. In the group with nonresorbable mesh, the diameter of the transposed PA remained stable throughout the observation period. At the end of the study, the diameter was very similar to that of the descending aorta. The autografts in the groups with resorbable material had minimal distension at day 1 , followed by a slight but significant increase in diameter over the course of 6 months. The mean diameter was $28 \pm 0.85 \mathrm{~mm}$, and no difference was found among the various resorbable materials.

In consideration of the fact that the Ross operation uses the pulmonary trunk transposition in the aortic root instead of the descending aorta, we performed another set of comparisons, taking as a reference the ascending aortic diameter. This diameter in the juvenile lamb was estimated in a study by Bonhoeffer and colleagues, ${ }^{26}$ and those values were used as a reference. At day 1, the diameter of the PA was equal to the ascending aortic diameter in all the groups that were reinforced, with resorbable or nonresorbable material. However, at 6 months, the use of a nonresorbable mesh precluded any progression in diameter, whereas in the group with resorbable mesh, the size of the autograft had slightly increased and was similar to that of the ascending aorta.

\section{Analysis at the Macroscopic and Microscopic Levels}

In the control group at 3 months (Figure 5, $A-C$ ), 1 aneurismal rupture occurred. Macroscopic specimens showed distension of the graft, and of the remnant of the ductus arteriosus and the intercostal arteries. A thrombus was occasionally observed by echography and at autopsy (Figure 5, A). Analysis at the microscopic level revealed serious damage to the vessel wall in all control cases. The 
No reinforcement

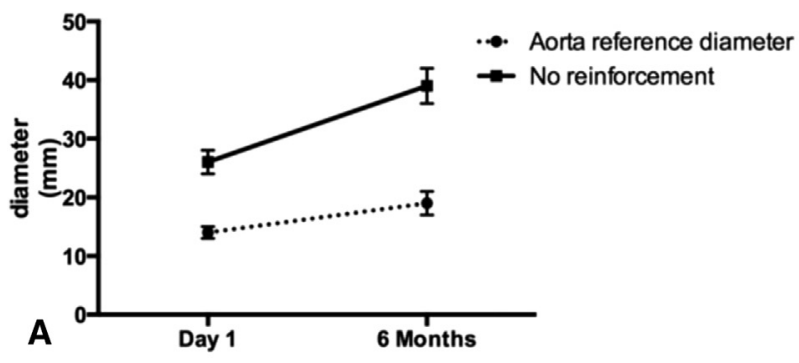

Non resorbable reinforcement

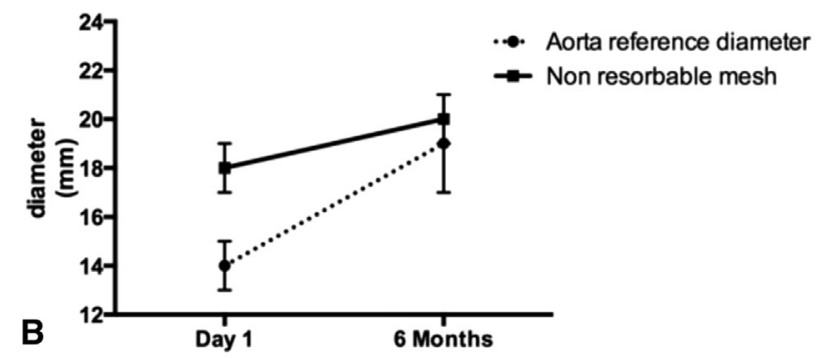

c

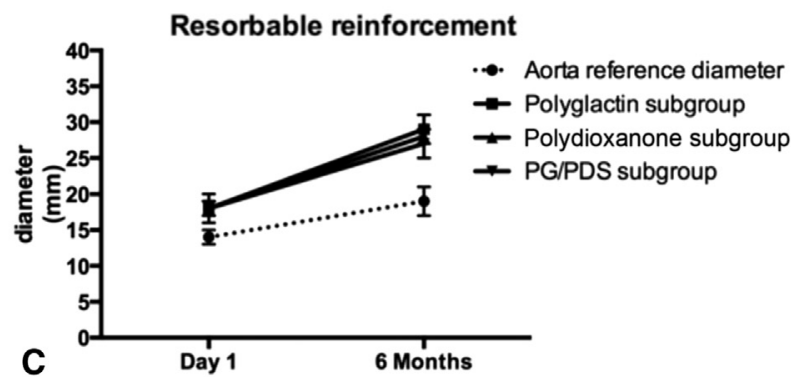

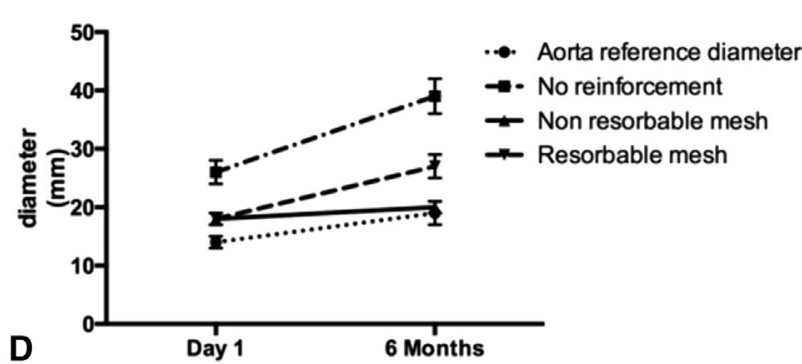

FIGURE 4. Pulmonary autograft diameter angiographic measurements compared with native aortic as reference diameter (see text): (A) groups with no reinforcement; (B) groups with nonresorbable reinforcement mesh; (C) subgroups with resorbable reinforcement mesh. No statistical differences were noted (see text). D, Comparison of all the reinforcement strategies used in the study. $P G$, Polyglactin; $P D S$, polydioxanone.

intima was the site of a severe hyperplasia. Thinning of the media, along with an inflammatory reaction and fibrosis of the adventitia, was noted. The media showed signs of being overstretched, and complete disruptions were frequently observed. The analysis at the microscopic level highlighted a considerable intimal hyperplasia with detachment from the media and focal calcification (Figure 5, B).

In the group with the nonresorbable reinforcement material, the PA diameter matched that of the descending aorta. However, when the graft was observed from the inside, the mesh was found to be visible and had partly migrated through the vessel wall (Figure 5,D). The intima was slightly thickened and the tunica media remained mostly intact, with the exception of the sites in which endoluminal migration of the mesh had occurred, where the vessel wall had thinned and was barely visible (Figure 5, E).

In contrast, all specimens reinforced with a bioresorbable mesh, independently of the material used, displayed a smooth endoluminal surface resembling that of the aorta (Figure 5, G). In the knitted PDS group, the thickness of the PA appeared to be normal. From a histologic standpoint, intimal hyperplasia was again present. The tunica media was perfectly intact, and the remnants of the slowly resorbable PDS suture were frequently seen in the adventitia (Figure 5, H). Masson's trichrome staining (Sigma-Aldrich, St. Louis, Mo) showed preservation of the endothelium and reorganization of the tunica media: Directly underneath the intima, smooth muscle cells were entwined with collagen fibers; deeper, collagen bundles became interwoven with elastic fibers, which formed a thick and highly organized layer of concentric lamellae. Tunica adventitia was formed by loose connective tissue with adipocytes (Figure 5, I). The control group (Figure 5,C) with the nonresorbable mesh (Figure 5, F) showed a compensatory hyperplastic response with medial hypertrophy and fiber disorganization. By comparison, the group with the resorbable materials displayed a more organized fiber network underlying a phenomenon of elastic remodeling of the PA wall.

\section{DISCUSSION}

The set of experimental activities described here represents the result of a wider experimental effort that was made to produce a reliable and reproducible model of the Ross operation. Given the anatomic constraints and technical issues with porcine models, we focused on the ovine model, which is more amenable to surgical handling. However, anatomic issues induced us to abandon the idea of a true reproduction of the Ross procedure. Several anatomic constraints led us to reconsider the initially adopted median sternotomy approach. These included the shortness of the ascending aorta and the pulmonary trunk, the extremely low position of the coronary ostia at the level of the valvular plane, and the hemodynamic instability and vulnerability of the lamb heart under cardiopulmonary bypass.

Given the unsatisfactory results and the impossibility of obtaining an effective and reproducible model with this approach, we moved to a more feasible transposition into the descending aorta of the actual pulmonary trunk. The rationale underlying this model relies on findings described by Bini and colleagues ${ }^{27}$ on the geometric relationship of the 

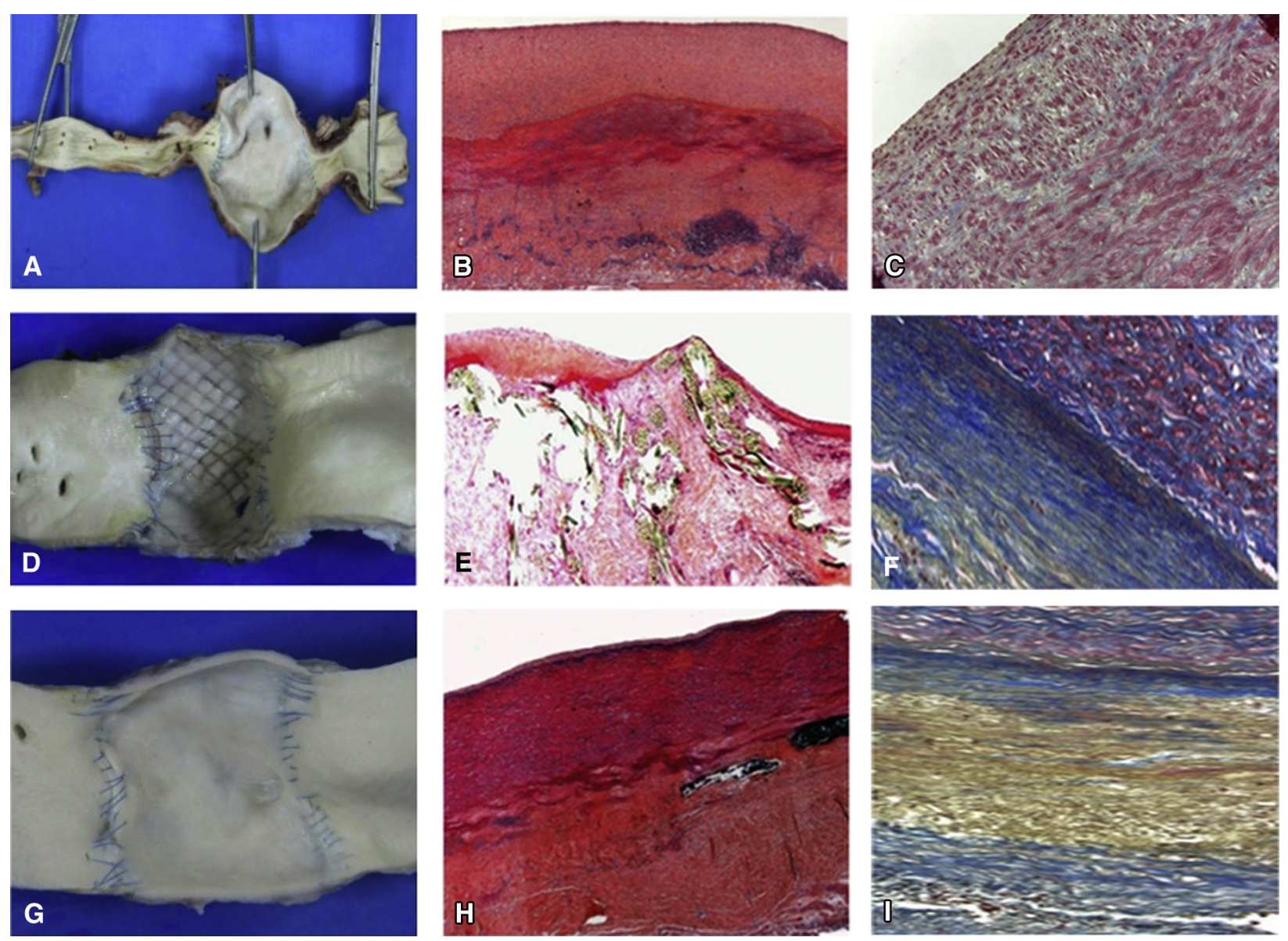

FIGURE 5. A-C, Control group. A, Macroscopic findings. B, Hematoxylin and eosin and (C) Masson's trichrome staining. Note (B) intimal hyperplasia, medial disruption, with (C) hyperplastic compensatory response and (B) signs of inflammation. D-F, Nonresorbable group. D, Macroscopic findings. E, Hematoxylin and eosin, and (F) Masson's trichrome staining. Note (D and E) mesh endoluminal transmigration and (F) muscular hyperplasia with fiber disorganization. G-I, Resorbable group. G, Macroscopic findings. H, Hematoxylin and eosin and (I) Masson's trichrome staining. Note (H) preservation of vessel architecture without strong inflammatory reaction, and (I) increase in fibrillar elastic component in yellow.

aorta and pulmonary artery during growth. The PA has been described as having 3 reference diameters: the pulmonary infundibulum with valve, pulmonary trunk, and its bifurcation. ${ }^{27}$ On the other side, the aortic root is characterized by the diameters of the annulus and the sinutubular junction. The pulmonary infundibulum, when placed in the aortic position, has an additional $30 \%$ potential for distensibility in respect to the native aortic root, allowing for a considerable degree of distortion without causing valve insufficiency. ${ }^{28} \mathrm{In}$ the freestanding neoaortic root replacement, the growth of the annulus is concurrent with the somatic growth, with no morphologic alteration of the leaflets, and the increases in its dimensions over time are adequate. ${ }^{29,30}$

In light of these observations, aortic regurgitation late after the Ross procedure might be explained mostly as being a result of a mismatch between somatic growth and the degree of dilation of the neosinuses and neosinutubular junction of the PA undergoing systemic pressure. ${ }^{16,31}$ However, Acar and colleagues ${ }^{32}$ showed that in childhood (ages 1-6 years), the aortic annulus and the sinutubular junction have the same diameter and index/ratio $=1$, and therefore the aortic root could be considered a regular cylinder. Therefore, we accept the descending aorta as a reliable surrogate for the aortic root, for those in childhood.

Clearly, the model is lacking a pivotal step of the Ross operation-one that concerns the coronary reimplanation. Unfortunately, the anatomic constraints and the hemodynamic vulnerability of the lamb conspired against the possibility of performing the procedure with the lamb in full cardioplegic arrest without jeopardizing the success and reproducibility of the model. However, we foresee the possibility of creating full-thickness holes through the autograft and the reinforcement, which is adhered to it, to allow coronary reimplantation. The current study was focused mainly on the development of an effective and reproducible model of pulmonary autograft transposition into the arterial system, with the aim of studying the behavior of the autograft and developing suitable strategies 
to prevent its future dilatation, which represents one of the major drawbacks of this operation. However, the aforementioned and other eventual strategies for coronary reimplantation mandate for further exploration in a successive of experiments.

The surgical approach used was safe, did not pose technical issues, and allowed us to perform long-term analysis on growing animals and to test various types of reinforcement strategies over time, to improve performance of the PA. As a continuation of our previous preliminary experimental effort, we tested the use of a resorbable reinforcement for the PA as an alternative to currently used synthetic materials. ${ }^{33}$ Resorbable materials were chosen for both their chemistry and biophysics characteristics. Polyglactin and PDS materials were selected as early- and late-resorbable materials, respectively, with an absorption time of $\sim 21$ days for the PG, and $\sim 6$ months for the PDS. In addition, PDS is the preferred suture material in pediatric cardiac surgery, especially for aortic coarctation correction.

The resorbable device allowed harmonious longitudinal and transversal growth, while precluding aneurysmal dilation of the neoaorta. As opposed to the results with the synthetic reinforcement, which elicited a strong inflammatory reaction with endoluminal migration of the mesh itself, the resorption of the bioprosthesis was accompanied by a minimal inflammatory reaction and seemed to trigger a phenomenon of wall matrix elastic remodeling of the autograft, shown by an increase in collagen and elastin fiber content. Analysis of the grafted pulmonary artery wall at the microscopic level showed a histologic pattern closely resembling that of the native aorta, and the increased elastic component might allow better hemodynamic performance in the long term. The particular mesh-fiber design, together with the vessel remodeling process triggered by the biomaterial, likely attenuated the pressure load exerted on the PA and compensated for the tendency toward dilation, assisting somatic growth and preventing aneurysmal degeneration.

The time frame of 6 months was chosen to match the resorption period of the resorbable materials and ensure that the somatic growth of the animal would reliably reflect the size increase and growth of human pediatric patients undergoing the Ross operation. Clearly, if this approach is to be translated to the clinical side, studies comprising a longer follow-up period and more evaluation intervals are required; and use of $\mathrm{CT}$ might be advocated as a more powerful and informative means of analysis of the morphostructural changes occurring in the PA during somatic growth.

We acknowledge that the sample size in the experimental group of animals is among the limitations of this study. However, the main aim of this study was to develop and fine-tune an animal model of PA transposition. In addition, the goal was to quickly screen a range of materials, to exclude those that are ineffective or toxic and select those that are more appropriate to be included in a following set of experiments, to develop an optimized bioprosthesis.

\section{CONCLUSIONS}

We developed a feasible and reproducible model of the Ross procedure in growing animals, allowing for a reliably accurate simulation of the clinical scenario. On the basis of this established model, we were additionally able to obtain interesting results on the use of bioresorbable material to reinforce a PA. This approach allowed for prevention of PA dilation while accommodating its viability and normal growth process, which favors vessel wall elastic remodeling.

We can reasonably speculate that the temporary interaction between the bioresorbable reinforcement and the PA orchestrated a complex process of vascular remodeling based on a balance between inflammation and extracellular matrix production. We can further speculate that this remodeling resulted, after biomaterial resorption, in a "neovessel" that exhibited characteristics similar to those of the aorta but was still biologically alive and capable of growth. Therefore, this process would allow induction of in vivo creation of a PA with morphostructural features enabling it to both face the hemodynamic load of the arterial system and guarantee a harmonious increase in size during somatic growth. Although results to confirm the current findings are needed, the use of biocompatible external reinforcements that are able to stimulate, guide, and improve the natural processes of biological graft remodeling and reaction to foreign materials, while accommodating tissue growth, may be key to solving some of the drawbacks of the Ross procedure.

\section{References}

1. Chambers JC, Somerville J, Stone S, Ross DN. Pulmonary autograft procedure for aortic valve disease: long-term results of the pioneer series. Circulation. 1997;96:2206-14

2. Ross D. Pioneers of cardiology: Donald Ross, DSc, FRCS. Interview by Mark Nicholls. Circulation. 2007;115:f33-4.

3. Elkins RC, Thompson DM, Lane MM, Elkins CC, Peyton MD. Ross operation: 16-year experience. J Thorac Cardiovasc Surg. 2008;136:623-30. e1-5.

4. David TE, David C, Woo A, Manlhiot C. The Ross procedure: outcomes at 20 years. J Thorac Cardiovasc Surg. 2014;147:85-93.

5. Brancaccio G, Polito A, Hoxha S, Gandolfo F, Giannico S, Amodeo A, et al. The Ross procedure in patients aged less than 18 years: the midterm results. J Thorac Cardiovasc Surg. 2014;147:383-8.

6. Konstantinov IE, d'Udekem Y, Brizard CP. Ross operation or aortic valve repair in neonates and infants? J Thorac Cardiovasc Surg. 2014;148:362-3.

7. Elkins RC, Lane MM, McCue C. Ross operation in children: late results. J Heart Valve Dis. 2001;10:736-41.

8. Sakaguchi H, Elkins RC, Lane MM, McCue C. Effect of prior aortic valve intervention on results of the Ross operation. J Heart Valve Dis. 2003;12:423-9.

9. Brown JW, Ruzmetov M, Shahriari A, Rodefeld MD, Mahomed Y, Turrentine MW. Midterm results of Ross aortic valve replacement: a singleinstitution experience. Ann Thorac Surg. 2009;88:601-7; discussion 7-8.

10. Elkins RC. The Ross operation: a 12-year experience. Ann Thorac Surg. 1999;68 S14-8.

11. Elkins RC, Knott-Craig CJ, Ward KE, Lane MM. The Ross operation in children: 10-year experience. Ann Thorac Surg. 1998;65:496-502. 
12. Elkins RC, Lane MM, McCue C. Ross procedure for ascending aortic replacement. Ann Thorac Surg. 1999;67:1843-5; discussion 53-6.

13. Elkins RC, Lane MM, McCue C, Chandrasekaran K. Ross operation and aneurysm or dilation of the ascending aorta. Semin Thorac Cardiovasc Surg. 1999;11:50-4.

14. Luciani GB, Favaro A, Viscardi F, Bertolini P, Mazzucco A. Valve-sparing root replacement for pulmonary autograft dissection late after the Ross operation. $J$ Thorac Cardiovasc Surg. 2004;128:753-6.

15. Kaya A, Heijmen RH, Vreuls W, Seldenrijk CA, Schepens MA. Chronic type A dissection in a pulmonary autograft. J Heart Valve Dis. 2007;16:162-4.

16. Brown JW, Ruzmetov M, Rodefeld MD, Mahomed Y, Turrentine MW. Incidence of and risk factors for pulmonary autograft dilation after Ross aortic valve replacement. Ann Thorac Surg. 2007;83:1781-7; discussion 7-9.

17. Brown JW, Fehrenbacher JW, Ruzmetov M, Shahriari A, Miller J, Turrentine MW. Ross root dilation in adult patients: is preoperative aortic insufficiency associated with increased late autograft reoperation? Ann Thorac Surg. 2011;92:74-81; discussion 81 .

18. Sievers HH, Hanke T, Stierle U, Bechtel MF, Graf B, Robinson DR, et al. A critical reappraisal of the Ross operation: renaissance of the subcoronary implantation technique? Circulation. 2006;114:I504-11.

19. Charitos EI, Takkenberg JJ, Hanke T, Gorski A, Botha C, Franke U, et al. Reoperations on the pulmonary autograft and pulmonary homograft after the Ross procedure: an update on the German Dutch Ross Registry. J Thorac Cardiovasc Surg. 2012;144:813-21; discussion 21-3.

20. Stulak JM, Burkhart HM, Sundt TM 3rd, Connolly HM, Suri RM, Schaff HV, et al. Spectrum and outcome of reoperations after the Ross procedure. Circulation. 2010;122:1153-8.

21. David TE. Ross procedure at the crossroads. Circulation. 2009;119:207-9.

22. Elder RW, Quaegebeur JM, Bacha EA, Chen JM, Bourlon F, Williams IA. Outcomes of the infant Ross procedure for congenital aortic stenosis followed into adolescence. J Thorac Cardiovasc Surg. 2013;145:1504-11.
23. Koul B, Al-Rashidi F, Bhat M, Meurling C. A modified Ross operation to prevent pulmonary autograft dilatation. Eur J Cardiothorac Surg. 2007:31:127-8.

24. Carrel T, Schwerzmann M, Eckstein F, Aymard T, Kadner A. Preliminary results following reinforcement of the pulmonary autograft to prevent dilatation after the Ross procedure. J Thorac Cardiovasc Surg. 2008;136:472-5.

25. Gebauer R, Cerny S. A modification of the Ross procedure to prevent pulmonary autograft dilatation. Eur J Cardiothorac Surg. 2009;36:195-7.

26. Bonhoeffer P, Boudjemline Y, Saliba Z, Hausse AO, Aggoun Y, Bonnet D, et al. Transcatheter implantation of a bovine valve in pulmonary position: a lamb study. Circulation. 2000;102:813-6.

27. Bini MND, Blackstone EH, Sievers H. Kirklin/Barratt-Boyes Cardiac Surgery. Vol 1. 2nd ed. London: Churchill Livingstone; 1993:34-5.

28. Vesely I, Casarotto DC, Gerosa G. Mechanics of cryopreserved aortic and pulmonary homografts. J Heart Valve Dis. 2000;9:27-37.

29. Hanke T, Stierle U, Boehm JO, Botha CA, Matthias Bechtel JF, Erasmi A, et al. Autograft regurgitation and aortic root dimensions after the Ross procedure: the German Ross Registry experience. Circulation. 2007;116:I251-8.

30. Horer J, Hanke T, Stierle U, Takkenberg JJ, Bogers AJ, Hemmer W, et al. Neoaortic root diameters and aortic regurgitation in children after the Ross operation. Ann Thorac Surg. 2009;88:594-600; discussion 600.

31. Charitos EI, Hanke T, Stierle U, Robinson DR, Bogers AJ, Hemmer W, et al. Autograft reinforcement to preserve autograft function after the Ross procedure: a report from the German-Dutch Ross Registry. Circulation. 2009;120: S146-54.

32. Acar C, Varnous S. In response to Kazui T, Izumoto H, Yoshioka K, Kawazoe K Dynamic morphologic changes in the normal aortic annulus during systole and diastole. J Heart Valve Dis. 2006;15:617-21, 843.

33. Nappi F, Spadaccio C, Castaldo C, Di Meglio F, Nurzynska D, Montagnani S, et al. Reinforcement of the pulmonary artery autograft with a polyglactin and polydioxanone mesh in the Ross operation: experimental study in growing lamb. $J$ Heart Valve Dis. 2014;23:145-8.

\section{EDITORIAL COMMENTARY}

\section{The continued evolution of a transformational operation: New options for wrapping the Ross autograft?}

\section{S. Adil Husain, MD}

See related article on pages 1134-42.

The Ross procedure for aortic valve replacement (AVR), first described by Donald Ross (Figure 1) in $1962^{1}$ and formally performed by him in 1967, offers numerous

From the Departments of Cardiothoracic Surgery and Pediatrics, University of Texas Health Sciences Center-San Antonio, San Antonio, Tex.

Disclosures: Author has nothing to disclose with regard to commercial support.

Received for publication Jan 10, 2015; accepted for publication Jan 12, 2015

Address for reprints: S. Adil Husain, MD, University of Texas Health Science Center at San Antonio, Cardiothoracic Surgery, 7703 Floyd Curl Dr, Mail Code 7841, San Antonio, TX 78229 (E-mail: husain@uthscsa.edu).

J Thorac Cardiovasc Surg 2015;149:1142-3

0022-5223/ $\$ 36.00$

Published by Elsevier Inc. on behalf of The American Association for Thoracic Surgery

http://dx.doi.org/10.1016/j.jtcvs.2015.01.076

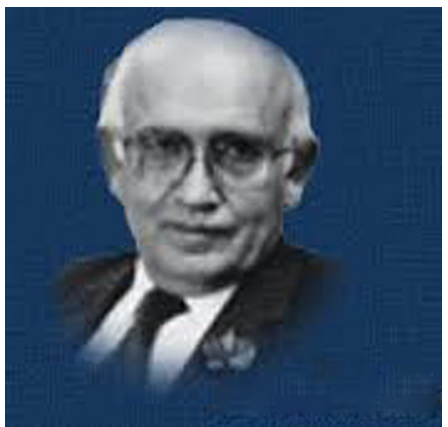

FIGURE 1. Donald Ross.

advantages in terms of an autograft prosthesis with characteristics of freedom from late calcification and stenotic degeneration, low endocarditis risk, and the avoidance of anticoagulation. This option for AVR remains well accepted 